\title{
The Effect of Stationary and Variable Electromagnetic Fields on the Germination and Early Growth of Radish (Raphanus sativus)
}

\author{
Malgorzata Konefal-Janocha ${ }^{1 *}$, Agnieszka Banaś-Ząbczyk², Mariusz Bester ${ }^{1}$, \\ Damian Bocak ${ }^{1}$, Sylwia Budzik¹, Szymon Górny¹, Stuart Larsen³, \\ Klaudiusz Majchrowski ${ }^{4}$, Marian Cholewa ${ }^{1}$
}
${ }^{1}$ Department of Biophysics, Faculty of Mathematics and Natural Sciences, University of Rzeszow, Rzeszow, Poland ${ }^{2}$ Department of Medical Biology, Chair of Preclinical Sciences, Faculty of Medicine,
University of Rzeszow, Rzeszow, Poland
${ }^{3}$ Norwegian Marine Research Institute, Bergen, Norway
${ }^{4}$ Department of Theoretical Physics, Faculty of Mathematics and Natural Sciences, University of Rzeszow, Rzeszow, Poland

Received: 19 October 2017

Accepted: 30 January 2018

\begin{abstract}
Magnetic fields have a great impact on processes within plants. In our experiment, radish seeds (Raphanus sativus) were exposed to a stationary magnetic field (with an intensity of $8 \mathrm{mT}$ and $20 \mathrm{mT}$ ) and variable magnetic fields (with an intensity of $6 \mathrm{mT}$ and a frequency of $50 \mathrm{~Hz}$ ). Two time intervals of exposure were selected: $3 \mathrm{~min}$ and $12 \mathrm{~min}$. After exposure, treated seeds were compared with the control seeds (without magnetic field exposure) in the following categories: seedling length, germination rate index (GRI), vigour index, and seed germination. The results revealed that magnetic fields increased the rate of germination, vigour index, and GRI for all samples treated with stationary magnetic field. It is difficult to distinguish a specific form of dependence between the measured parameters and the intensity of the magnetic fields and the selected time intervals. The most promising results were obtained from the sample that was exposed to a stationary magnetic field intensity of $20 \mathrm{mT}$ at $12 \mathrm{~min}$. All measured values decreased when the seeds were exposed to variable magnetic fields at the exposure time of $12 \mathrm{~min}$.
\end{abstract}

Keywords: electromagnetic field exposure, seed germination, germination rate index, plants in the electromagnetic field

*e-mail: mk_janocha@wp.p 


\section{Introduction}

Urban areas and the rapid progress of industrialization and technology are leading to serious air pollution in urban areas. In particular, people trying to maintain urban lifestyles are harming health. In Europe, more than two-thirds of the total population lives in cities. Population growth and industrialization have led to air pollution in some cities that reaches levels that threaten health. This has become one of the most important topics of our day. Human health is affected by all air pollution, but some emissions have more severe atmospheric conditions. In particular, carbon dioxide $\left(\mathrm{CO}_{2}\right)$ and other pollutants, which drive global warming, have recently attracted attention, and $\mathrm{CO}_{2}$ has become one of the most researched gases. Recent studies show PM10 and PM2.5 $\mathrm{CO}_{2}$ air quality indices. There are a lot of studies for carbon emissions, including indoor and outdoor especially cities and urban parks. This shows that PM2.5 has affected human health. Solar radiation in urban areas are also affect human health. Indoor plants are effected by solar radiation, which leads to climate change in the environment as well as forest, coastal, and urban areas. A recent study shows that plant performance is affected by ecological and economic as well as chemical searches. Physical performance of plants are more effective. Thus, it demands natural and cultural areas and coastal areas [1-11].

In modern times, as we seek new ecological and economical methods for increasing the performance and capability of plants, magnetic stimulation is an interesting alternative to chemical methods. Physical methods of plant stimulation are not only more profitable, but they also greatly improve the performance of plants without harming the environment.

Research on the influence of magnetic fields on biological systems began many decades ago, with recent detailed reviews provided by Maffei [12] and Teixeira da Silva and Dobránszki [13]. As both studies noted, there are many contradictory studies regarding the influence of magnetic fields on biological systems, and there is a pressing need to understand the actual mechanisms involved, if any.

Vashisth and Joshi [14] made an experiment in which seeds of maize were exposed to static magnetic fields of strength 50,100,150,200, and 250 for 1, 2, 3, and $4 \mathrm{~h}$ for all field strengths. Results indicate that magnetic field application enhanced seed performance in terms of percentage germination, speed of germination, seedling length, and seedling dry weight significantly compared to unexposed control. Among the various combinations of field strength and duration, $200 \mathrm{mT}$ for $1 \mathrm{~h}$ exposure gave best results.

Other studies, however, have reported effects especially in relation to the reduction of germination time of seeds exposed to a variety of magnetic field intensities in both $\mathrm{AC}$ (alternating current) and DC (direct current) conditions. For example, Haq et al. [15] have found that exposure to 40,80 , and $110 \mathrm{mT}(2.5,5$, and
10 min respectively), resulted in no significant change in germination time except for that of the highest magnetic field (110 $\mathrm{mT}$ exposure for $10 \mathrm{~min}$ ) where the germination time was reduced $(p=0.05)$.

Another interesting experiment was conducted by Kirdan et al. [16]. In their study, the effects of magnetic field on the germination of seeds and growth of seedlings of stone pine (Pinus Pinea L.) were investigated. For this purpose, its seeds were treated by a magnetic field of $9.42 \mathrm{mT}$ for a different period of time: $0 \mathrm{~min}$ (control), $15 \mathrm{~min}, 30 \mathrm{~min}$, and $40 \mathrm{~min}$. Considering the germination results as a whole, seeds exposed to a magnetic field for 30 and 45 minutes resulted in higher germination energy and percentage of germination, respectively. Magnetic field increased shoot height, root collar diameter, and also tap root length of stone pine seedlings.

In the search for improved germination of zinnia (Zinnia elegans Jacq.), Afzal et al. [17] also experimented with the magnetic field. A lab study was conducted to investigate the potential of magnetic seed stimulation as a seed enhancement tool and its influence on germination and emergence capacity of zinnia. Magnetic seed treatment with 50,100, and $150 \mathrm{mT}$ strength each for 5 , 10 , and 15 min. was compared with control (untreated). Magnetic seed stimulation reduced time to $50 \%$ germination and mean germination time and increased final germination percentage, germination energy, and germination index. Root length, shoot length, seedling fresh, and dry weight was also increased as a result of magnetic seed stimulation. Furthermore, magnetic field treatment also enhanced $\alpha$-amylase activity, total soluble sugars, and reducing sugars levels. Among all seed treatments, the magnetic field with a strength of $100 \mathrm{mT}$ for $15 \mathrm{~min}$ was the most effective physical treatment for improving seed germination and seedling growth of zinnia.

Matsuo and Furuya [18] have found a minimal reduction in the germination time of radish seeds exposed to 30,60 , and $120 \mathrm{mT}$, similar to Krawiec et al. [19, 20].

Mahajan and Pandey [21] noticed that seeds of bitter gourd (Momordica charantia) after being treated with electric and magnetic fields, saw an increase in the yield. The seeds were exposed to $300,500,700$, and $1000 \mathrm{~V} / \mathrm{cm}$ electric field for $20 \mathrm{~min}$. The results showed that electric field stimulates germination of bitter gourd seeds positively at low levels and has a resonating effect at $500 \mathrm{~V} / \mathrm{cm}$. At higher electric fields, the germination was decreased sharply. Seeds of bitter gourd were also exposed in batches to static magnetic fields of $0.07,0.12$, 0.17 , and $0.21 \mathrm{~T}$ for $20 \mathrm{~min}$. The seeds respond differently when exposed to a magnetic field, showing continuous positive stimulation under all applied fields.

In other studies using chickpea (Cicer arietinum), Vashisth and Nagarajan [22] found that exposure of seeds to magnetic fields enhanced the speed of germination. Vashisth and Nagarajan tested if there were any dose-response effects for different levels of magnetic fields $(0-250 \mathrm{mT})$ or exposure time, but this was not evident. Two years later, the same group conducted 
an analogous experiment, but this time they used sunflower seeds (Helianthus annuus) [23]. Among the magnetic fields tested, the results for the combination of $50 \mathrm{mT}$ and $200 \mathrm{mT}$, with time intervals of up to $2 \mathrm{~h}$, were the most promising. Treated seeds revealed increased parameters such as dry mass, length of roots, area of roots, and capacity of roots, primarily in 1-month-old seedlings compared with the control sample.

Ahamed [24] and his research team conducted experiments with sweet pepper (Capsicum annuum L.) seeds. A study was carried out to understand the effect of magnetic field on seed germination, growth, yield, and fruit quality of this plant. Pepper seeds or irrigated water (separately or together) were passed through a magnetic funnel. Percentage germination rate, growth and yield parameters of treated and non-treated pepper plants were recorded. The obtained results indicated that magnetic field is an effective method for the pre-sowing treatment of the seeds that enhance their germination and increase yield capacity and fruit quality.

Efthimiadou et al. [25] studied the effects of pulsed electromagnetic fields with an amplitude intensity of $12.5 \mathrm{mT}$, taking into account three exposure times, i.e., 5,10 , and $15 \mathrm{~min}$. on tomato seeds. The yield per plant was higher in magnetic field treatments compared to the control group. The MF-15 treatment yield was $81 \%$ higher than the control treatment. Lycopene content was higher in magnetic field treatments, although values showed no statistically significant differences.

A difficulty in interpreting the results of these and other studies is disentangling possible confounding effects that may arise from using seeds with a different shape, size, coat thickness, dielectric constant, and the mixture of studies using either AC or DC magnetic fields. This can be further complicated since the exact mechanisms by which magnetic fields might affect the seed are not yet understood. For example, the monocotyledonous wheat seed is elongated, with a high starch content and the genetic component of the seed located near the end. Under intense AC magnetic fields (which also induce electric currents) as well as potential heating effects, such a seed might be expected to behave differently compared to, for example, a chickpea seed, which is much larger, approximately spherical, and dicotyledonous, with higher protein and fat contents and very different dielectric behavior, and with the genetic material contained much deeper within the seed, where it is less likely to dissipate any heat or other induced stimulation. With reference to this research, we would like to investigate if there is any difference in measured effects from using either a stationary and sinusoidal variable magnetic field for radish seeds at short time intervals (because a long exposure time is associated with a significant temperature increase in the magnetic field generator, which we would like to exclude).

The aim of this study was to evaluate the effects of $\mathrm{AC}$ and DC magnetic fields on radish (Raphanus sativus) seed germination, vigour index, germination rate index (GRI), and seedling length.

\section{Experimental}

\section{Preparation of Plant Material}

Radish seeds (Raphanus sativus L.) for all experiments were obtained from the Diet Food Company (Warsaw, Poland). They were not treated with chemicals and had uniform germination rates with the same batch of seeds used for all experiments. Seeds were selected on the basis of having no visible defects, deformities, or the presence of insects. In order to determine the moisture content of the seeds, they were placed in an oven at $95^{\circ} \mathrm{C}$ for $24 \mathrm{~h}$ [26]. The seeds were weighed before and after the drying process. Their moisture content was measured using the following formula

$$
\text { moisture content }=\frac{\mathrm{W}_{1}-\mathrm{W}_{2}}{\mathrm{~W}_{2}} \cdot 100 \%,
$$

...where $\mathrm{W}_{1}$ is seed weight before drying and $\mathrm{W}_{2}$ is seed weight after drying. The water content of the seeds at the beginning of the experiment was at $4.85 \%$.

\section{Magnetic Field Generation and Seed Treatment}

A magnetic field generator was designed at the Department of Biophysics at the University of Rzeszow. The solenoid was made in a cylindrical shape with a diameter of $8 \mathrm{~cm}$ and a length of $20 \mathrm{~cm}$ and consisted of 1903 coils of $1 \mathrm{~mm}$ copper wire. The resistance of the coil was $12.6 \Omega$ with an inductance of $145 \mathrm{mH}$. Depending on the power supply (AC/DC), the effects of either stationary (DC) or variable (AC) magnetic fields could be investigated. The construction of the solenoid and the power supply permitted a maximum input of $25 \mathrm{~V}$ and $2 \mathrm{~A}$. The solenoid had a hole in its geometrical centre in order to gauge intensity levels using a Teslameter. The solenoid was able to generate intensity levels in the range of 0-22 $\mathrm{mT}$ for stationary fields and 0-9 $\mathrm{mT}$ for variable fields. The frequency in all variable (AC) fields was $50 \mathrm{~Hz}$ and the system is shown in Fig. 1.

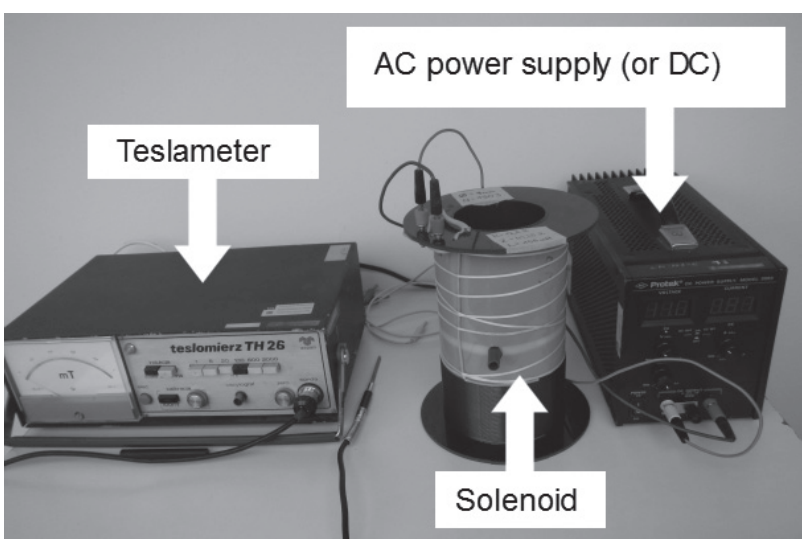

Fig. 1. Magnetic field generator used in the experiment. 
Table 1. Overview of parameters of specific samples.

\begin{tabular}{|c|c|c|c|}
\hline $\begin{array}{c}\text { Sample } \\
\text { number }\end{array}$ & $\begin{array}{c}\text { Intensity } \\
{[\mathrm{mT}]}\end{array}$ & $\begin{array}{c}\text { Exposure time } \\
{[\mathrm{min}]}\end{array}$ & Field type \\
\hline $\mathrm{C}$ & \multicolumn{3}{|c|}{ Control sample - no electromagnetic field } \\
\hline 1 & 8 & 3 & DC \\
\hline 2 & 8 & 12 & DC \\
\hline 3 & 20 & 3 & DC \\
\hline 4 & 20 & 12 & DC \\
\hline 5 & 6 & 3 & AC \\
\hline 6 & 6 & 12 & AC \\
\hline
\end{tabular}

Dry radish seeds (50 seeds in each replicate) were placed in a Petri dish with a diameter of $60 \mathrm{~mm}$ and then inserted into the generator. The chosen parameters of the field were 8 and $20 \mathrm{mT}$ for the stationary field and $6 \mathrm{mT}$ for the variable field. The time of exposure for the above values was set to 3 and $12 \mathrm{~min}$. Detailed descriptions of the individual samples are listed in Table 1. Every combination of intensity and time of exposure for each experimental treatment was replicated 3 times. The intensity of the magnetic field was controlled using the interface of the current generator and measured with the probe of the Teslameter inside the solenoid. Before stimulation with the magnetic field the seeds were placed at equal distances from each other in Petri dishes on a lining. We chose this substrate based on research by Domaradzki and Kopal, who showed that it is expedient in laboratory conditions [27]. After stimulation they were cultured at room temperature for the following 9 days. On each of the following 9 days, once every $24 \mathrm{~h}$ at the same time the samples were watered with an equal volume of water and the newly germinated seeds were counted. On this basis we calculated the GRI.

a)

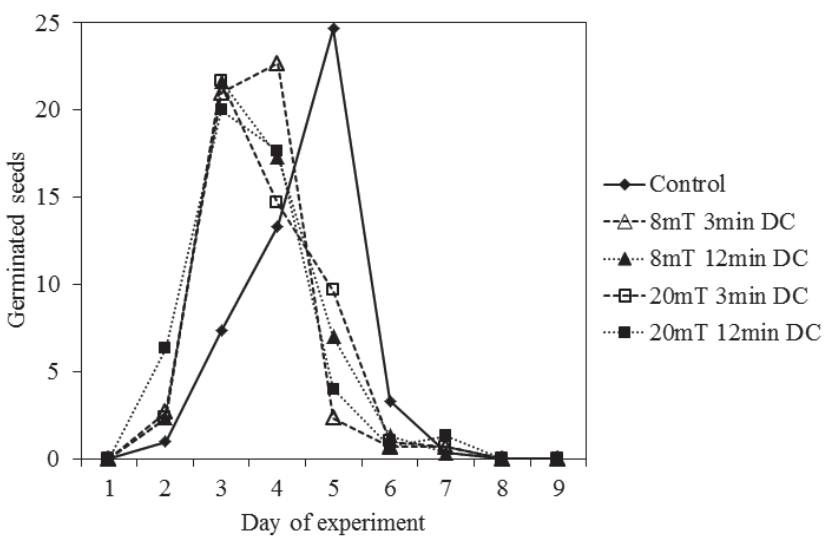

\section{Seed Germination}

Seed germination was determined as the percentage of seeds that sprouted relative to the total number of seeds in place (excluding those that have not germinated, were deformed, or had died). After 9 days of cultivation, the seeds were measured using a caliper gauge and the stem and root lengths $(\mathrm{mm})$ of all the seeds that germinated were measured. The seedling length was defined as the sum of the root and shoot length. Seedling vigour was calculated following Abdul-Baki and Anderson [28] as:

$$
\begin{aligned}
& \text { vigour index = germination }(\%) \times \\
& \times \text { seedling length }(\text { root }+ \text { shoot }),
\end{aligned}
$$

On every day of the experiment the number of germinated seeds was counted. Based on this data, the germination rate index (GRI) [29] was calculated using the following formula

$$
\mathrm{GRI}=\frac{\text { number of seeds germinated }}{\text { day of the first count }}+\ldots+
$$

\section{Statistical Analysis}

The data were analyzed using STATISTICA software. Following the methods of Lilliefors and Shapiro-Wilk (tests of normality distribution), the measured length of the root, length of the shoot, and seedling length in the vast majority of cases were found not to be normally distributed and the $p$ value for almost all cases was less than the level of significance $\alpha=0.05$. Therefore, a one-way ANOVA Kruskal-Wallis Rank (ANOVA Kruskal-Wallis) technique was used with the null hypothesis: $\mathrm{H}_{0}$ - being that the level of growth of the radish was the same for each category of the magnetic

b)

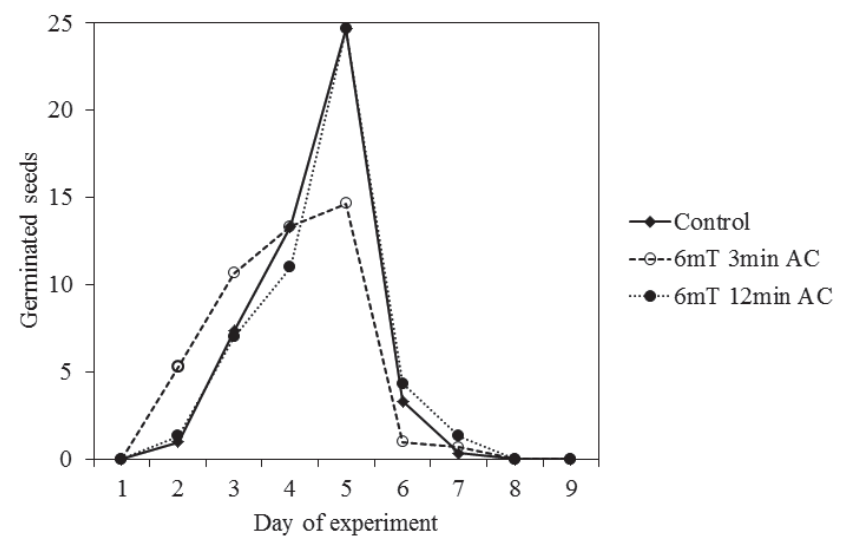

Fig. 2. Number of radish seeds germinated on each day of experiment ( $\mathrm{a}-$ for $\mathrm{DC} ; \mathrm{b}-$ for AC). 


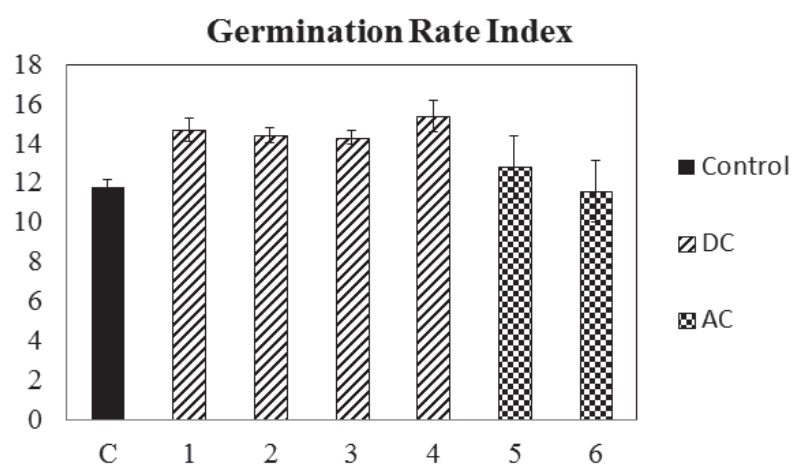

Fig. 3. Germination rate index for individual samples (see Table 1; bars represent the standard error for each of the values).

field, versus $\mathrm{H}_{1}$ - that at least one category of the magnetic field resulted in a different level of growth.

\section{Results and Discussion}

We cultivated radish seeds and characterized their growth by several parameters and here we compare the results of our experiments. First, every day of the experiment (each $24 \mathrm{~h}$ for 9 days), we counted the newly germinated seeds, examining the germination rates for each day of the experiment. Figs 2a) and 2b) show a remarkable difference between seeds exposed to a magnetic field versus control treatments. In the case of the stationary magnetic field (DC) treatment (both 3 and $12 \mathrm{~min}$ ), the germination of radish seeds started 1-2 days earlier than non-treated control seeds (Fig. 2a). In the case of variable magnetic field (AC), there appeared to be no effect (Fig. 2b). The magnetic field exposure - root mean square corrected (RMS) was lowest in the AC treatments, and it may therefore be that some threshold of magnetic field intensity value exists, below which no effect is seen and that the field produced in the AC experiments was below this threshold. If this were the case it may explain some of the variation in results of the studies described in the

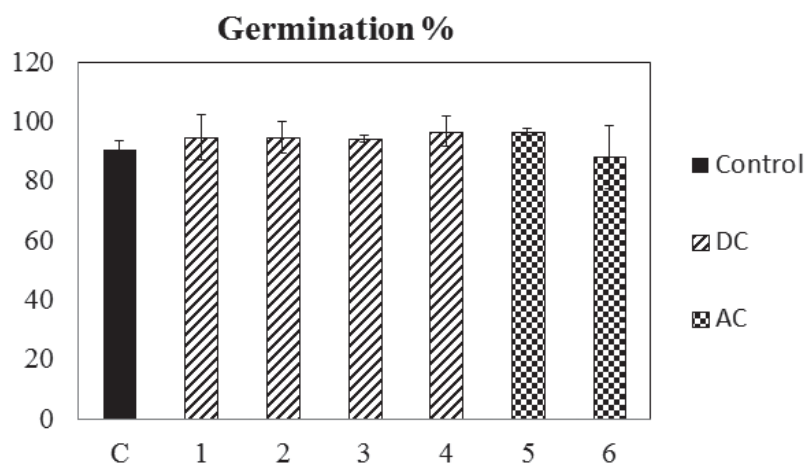

Fig. 4. Percentage of germinated seeds for each sample on the last day of cultivation (see Table 1; bars represent the standard error for each of the values).

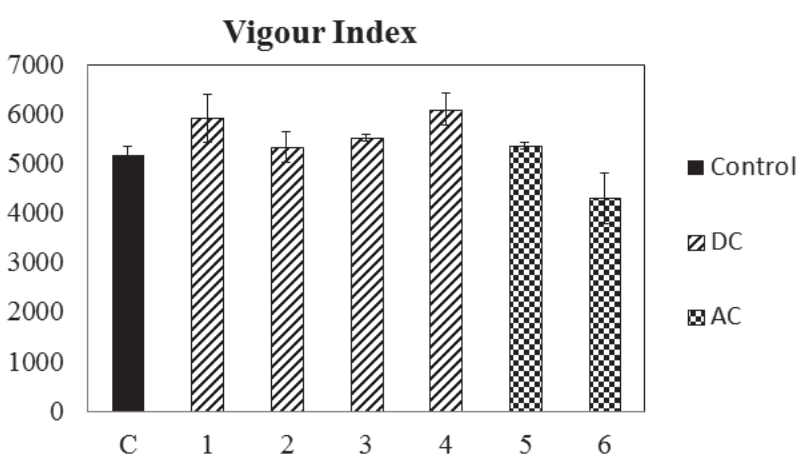

Fig. 5. Vigour index for each sample (see Table 1; bars represent the standard error for each of the values).

introduction, although the values cited were all higher than the DC values we used in this study. Alternatively, there may be some negative effect caused by the AC

field inducing an electrical current within the seed, which counters any beneficial changes due to the magnetic field.

We also calculated GRI (Formula 3), with the results shown in Fig. 3. Clearly, for all treatments using the DC electromagnetic field, the GRI was enhanced (9-22\%). Also, in the case of $6 \mathrm{mT} 3 \mathrm{~min}$ AC treatment, the GRI was higher than in control, although not significant. In the case of AC, electromagnetic field changes are within the limits of statistical error.

On the last day of the experiment we obtained the total number of germinated seeds. The results are shown in Fig. 4. For all the samples, no significant changes in the final number of germinated seeds were observed. In the early stage we can observe statistically significant differences in speed of germination, especially in the all samples treated with SMF. By the $9^{\text {th }}$ day of the experiment any differences are compensated for, because almost all of the seeds are germinated.

On the last day of each experiment we measured the length of the whole plant (as the sum shoot + root) and the data are shown in Fig. 6.

As previously mentioned, the measured length of the root, shoot, and the sum of them together are

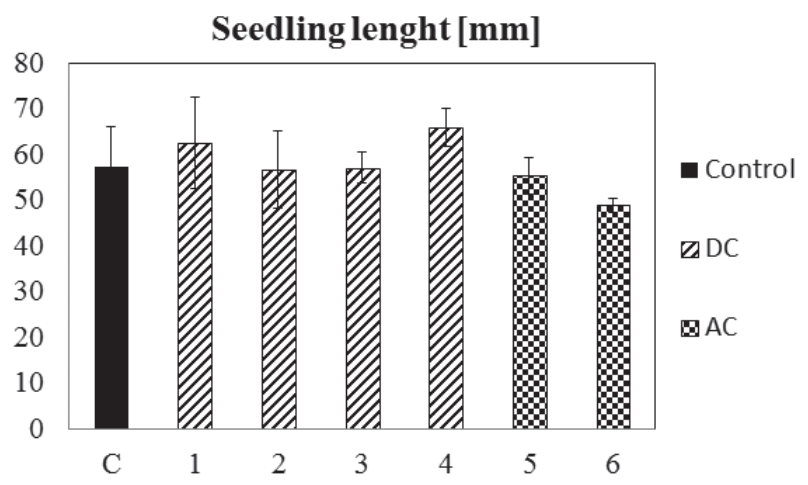

Fig. 6. Average value of seedling length (see Table 1; bars represent the standard error for each of the values). 
Table 2. Value of parameter $p$ for the length of the radish seedlings for each sample $\left({ }^{*} \mathrm{p}<0.05\right)$.

\begin{tabular}{|c|c|c|c|c|c|c|c|}
\hline & Control & Sample 1 & Sample 2 & Sample 3 & Sample 4 & Sample 5 & Sample 6 \\
\hline$p$-value & - & 0.19419 & 0.274756 & 0.585483 & $0.042802 *$ & 0.612199 & $0.018612 *$ \\
\hline
\end{tabular}

generally not normally distributed, and for this reason statistical significance was tested using a one-way ANOVA Kruskal-Wallis Rank. The determined value of parameter $p=0.000151$ demonstrated that there was a significant difference in the total length of radish seedlings (root + shoot) between the compared categories of the applied magnetic field. The analysis POST-HOC Conover-Iman clearly indicates that there are significant differences between the lengths of plants without electromagnetic fields, the radishes stimulated by the static field with an intensity of $20 \mathrm{mT}$ for $12 \mathrm{~min}$, and the variable field with an intensity of $6 \mathrm{mT}$ for $12 \mathrm{~min}$. In the first case we noted an increase in the length of the radish seedlings, and in the second a decrease in the length of radishes relative to the control. The values of parameter $p$ for each sample are listed in Table 2 .

Using formula 2 we calculated the vigour index and the results are presented in Fig. 5. It can be noted that samples 1 and 4 have received an increase in their vigour index, and sample 6 a decline in the value of the calculated parameter. In other cases, no change was perceived.

\section{Conclusions}

The treatment of the dry seeds with stationary and variable magnetic fields within the chosen parameters gave a variety of results in response to the type of field, its intensity, and exposure time. From our results we can conclude that exposure to the stationary magnetic field used in our experiments ( $8 \mathrm{mT}$ and $20 \mathrm{mT}$ ) to stimulate dry seeds before seeding (for 3 and 12 min) significantly improved germination rate and increased GRI and seedling length. Increases in seedling length, however, may simply reflect the earlier germination of the seeds treated with the magnetic field, and which therefore had one extra day of growth relative to the control seedlings.

For the variable magnetic field treatments, we cannot conclude any affects due to the magnetic field exposure because our results were not statistically significant.

Statistical analysis revealed that the average length of the whole plant was higher for the samples treated in the static electromagnetic field with an intensity of $20 \mathrm{mT}$ for $12 \mathrm{~min}$ (Sample 4) (Fig. 6). For samples that use alternating magnetic fields, the exposure appeared to reduce the length of the seedlings. Compared with the vigour index, which is dependent on the percentage of germinated seeds and the average length of seedlings, positive changes were noted only for the static field of $8 \mathrm{mT}$ for $3 \mathrm{~min}$ (Sample 1) and $20 \mathrm{mT}$ for $12 \mathrm{~min}$ (Sample 4). For a variable field rate of $6 \mathrm{mT}$ for $12 \mathrm{~min}$ (Sample 6), again we noticed a decrease.
In conclusion, the most promising parameters in this experiment were the stationary magnetic fields of $8 \mathrm{mT}$ at $3 \mathrm{~min}$ and $20 \mathrm{mT}$ at $12 \mathrm{~min}$. The variable magnetic field has a negative influence on germination and the early growth of the radish. The growth enhancement seen in the parameters we measured does not appear to be linearly dependent on intensity or time of exposure, possibly suggesting a "threshold" in response to magnetic field intensity. The best combinations of the above parameters need to be determined precisely in forthcoming work. In particular, it would be very interesting to find the threshold limit of the electromagnetic field from which the effect arises, if such a limit exists. As for further studies, it would be interesting to evaluate whether and how long after exposure to the electromagnetic field seeds can be stored effectively. In our future research, we will strive to study these aforementioned issues and whether there have been any genetic alterations in specific genes in material isolated from seedlings after MF stimulation.

\section{Acknowledgements}

This study was performed within the project "Center for Innovation and Transfer of Natural Sciences and Engineering Knowledge" by the University of Rzeszow, cofinanced within the Regional Operational Program for Podkarpackie Province for the years 2007-2013, contract number UDA-RPPK.01.03.00-18-001/10-00.

\section{Conflict of Interest}

The authors declare no conflict of interest.

\section{References}

1. CETIN M., SEVIK H. Measuring the Impact of Selected Plants on Indoor $\mathrm{CO}_{2}$ Concentrations. Polish Journal of Environmental Studies, 25 (3), 973, 2016.

2. CETIN M., SEVIK H., SAAT A. Indoor Air Quality: the Samples of Safranbolu Bulak Mencilis Cave. Fresenius Environmental Bulletin. 26 (10), 5965, 2017.

3. GUNEY K., CETIN M., GUNEY K.B., MELEKOGLU A. The Effects of Some Hormones Applications on Lilium martagon L. Germination and Morpholgical Characters. Polish Journal of Environmental Studies. 26 (6), 1, DOI: 10.15244/pjoes/70895, 2017.

4. CETIN M, SEVIK H, ISINKARALAR K. Changes in the particulate matter and $\mathrm{CO}_{2}$ concentrations based on the time and weather conditions: the case of Kastamonu, Oxidation Communications, 40 (1-II), 477, 2017. 
5. CETIN M. A Change in the Amount of $\mathrm{CO}_{2}$ at the Center of the Examination Halls: Case Study of Turkey. Studies on Ethno-Medicine 10 (2), 146, 2016.

6. CETIN M., SEVIK H. Change of air quality in Kastamonu city in terms of particulate matter and $\mathrm{CO}_{2}$ amount. Oxidation Communications 39, No 4-II, 3394, 2016.

7. SEVIK H., CETIN M. Effects of Water Stress on Seed Germination for Select Landscape Plants. Polish Journal of Environmental Studies, 24 (2), 689, 2015.

8. CETIN M. Using GIS analysis to assess urban green space in terms of accessibility: case study in Kutahya. International Journal of Sustainable Development \& World Ecology, 2015, 22 (5), 420, 2015.

9. YUCEDAG C., KAYA L.G., CETIN M. Identifying and assessing environmental awareness of hotel and restaurant employees' attitudes in the Amasra District of Bartin. Environmental Monitoring and Assessment, 190 (2), 60, doi: 10.1007/s10661-017-6456-7, 2018.

10. YIGIT N., SEVIK H., CETIN M., KAYA N. Chapter 3: Determination of the effect of drought stress on the seed germination in some plant species, Water Stress in Plants, Intech Open, Eds: Ismail Md. Mofizur Rahman, Zinnat Ara Begum, Hiroshi Hasegawa, ISBN:978-953-51-2621-8, pp: 43-62 (126), 2016.

11. CETIN M. Chapter 27: Landscape Engineering, Protecting Soil, and Runoff Storm Water, InTech-Open ScienceOpen Minds, Online July 1st, 2013. Book: Advances in Landscape Architecture-Environmental Sciences, ISBN 978-953-51-1167-2, 697., 2013.

12. MAFFEI M. Magnetic field effects on plant growth, development, and evolution. Frontiers in Plant Science, 5, doi:10.3389/fpls.2014.00445, 2014.

13. TEIXEIRA DA SILVA J.A., DOBRÁNSZKI J. Magnetic fields: how is plant growth and development impacted? Protoplasma, 253, 231, 2016.

14. VASHISTH A., JOSHI D.K. Growth characteristics of maize seeds exposed to magnetic field. Bioelectromagnetics, 38: 151, 2017.

15. HAQ Z., JAMIL Y., IRUM S., RANDHAWA M.A., IQBAL M., AMIN N. Enhancement in germination, seedling growth and yield of Radish (Raphanus sativus) using seed pre-sowing magnetic field treatment. Polish Journal of Environmental Studies, 21 (2), 369, 2012.

16. KIRDAN E., YUCEDAG C., BALABAN B. The effects of magnetic fields on germination of seeds and seedling of stone pine. Journal of forests, 3 (1), 1, 2016.

17. AFZAL I., ABBASI K.Y., IQBAL A., YOUNIS A., BAKHTAVAR M.A., REHMAN H. U. Enhancement of zinnia seed germination and seedling emergence through magnetic seed stimulation. Acta Sci. Pol. Hortorum Cultus, 15 (5), 173, 2016.

18. MATSUO M., FURUYA H. Effects of cyclical exposure to magnetic field on germination and growth of radish seed. Environmental Control in Biology. 32 (1), 25, 1994, [In Japanese].

19. KRAWIEC M., DZIWULSKA-HUNEK A., KORNARZYŃSKI K., PALONKA S. Wpływ wybranych czynników fizycznych na kiełkowanie nasion rzodkiewki (Raphanus sativus L.). Acta Agrophysica, 19 (4), 737, 2012 [In Polish].

20. KRAWIEC M., KORNARZYŃSKI K., PALONKA S., KAPLAN M., BARYLA P., KICZOROWSKI P. Does the magnetic field improve the quality of radish seeds? Acta Scientiarum Polonorum Hortorum Cultus, 12 (6), 93, 2013.

21. MAHAJAN T.S., PANDEY O.P. Effect of electric and magnetic treatments on germination of bitter gourd (Momordica charantia) seed. International Journal of Agriculture and Biology, 17 (2), 2015.

22. VASHISTH A, NAGARAJAN S. Exposure of seeds to static magnetic field enhances germination and early growth characteristics in chickpea (Cicer arietinum L.). Bioelectromagnetics, 29 (7), 571, 2008.

23. VASHISTH A., NAGARAJAN S. Effect on germination and early growth characteristics in sunflower (Helianthus annuus) seeds exposed to static magnetic field. J Plant Physiol, 167, 149, 2010.

24. AHAMED M.E.M., ELZAAWELY A. A., BAYOUMI Y.A. Effect of mMagnetic field on seed germination, growth and yield of sweet pepper (Capsicum annuum L.). Asian Journal of Crop Science, 5, 286, 2013.

25. EFTHIMIADOU A., KATSENIOS N., KARKANIS A., PAPASTYLIANOU P., TRIANTAFYLLIDIS V., TRAVLOS I., BILALIS D.J. Effects of presowing pulsed electromagnetic treatment of tomato seed on growth, yield, and lycopene content. The Scientific World Journal, Volume 2014, Article ID 369745, 6 pages, 2014.

26. WALTERS C. Understanding the mechanism and kinetics of seed ageing. Seed Sci Res, 8, 223, 1988.

27. DOMORADZKI M., KORPAL W. Analiza kiełkowania nasion otoczkowanych rzodkiewki $\mathrm{z}$ zastosowaniem czterech wybranych rodzajów podłoża. Inżynieria Rolnicza R. 13, Vol. 2 (2009), 27, 2009 [In Polish].

28. ABDUL-BAKI A.A., ANDERSON J.D. Vigour determination in soybean by multiple criteria. Crop Sci, 10, 31, 1973.

29. MAGUIRE J.D. Speed of germination - aid in selection and evaluation for seedling emergence and vigour. Crop Sci., 2, 176, 1962. 
